\title{
Commonplace
}

\section{Set Them Free}

\section{Dasapta Erwin Irawan ${ }^{1}$, Juneman Abraham²}

${ }^{1}$ Lecturer and active researcher in hydrogeology working at Institut Teknologi Bandung, Cofounder of The RINarxiv,

${ }^{2}$ Lecturer and active researcher in psychology working at Bina Nusantara University

Published on: Mar 30, 2021

DOI: $10.21428 / 6 \mathrm{ffd} 8432.5 e e 70 f 55$

License: Creative Commons Attribution 4.0 International License (CC-BY 4.0). 
... If you love someone, set them free

-Sting 1
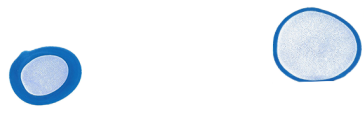

\section{Academics are objects}

When you love your country, you do things to keep them free from the new age of imperialism. Imperialism has come to the point that anyone who wishes to be promoted is requested to speak and write in a language which they don't natively speak. All of this is in the name of international recognition. Various offers - be they - calls for a paper or a book, invitations to webinars on how to publish in high impact journals, bundled subscription for access to databases and paywalled journals, to editing services - are flowing to the email inbox of Indonesian academics practically daily. The senders are publishers, paid database indexing service, and also companies providing editing services. Not only individuals are targeted, but also institutions. Academics are now merely the object not the subject in the development of knowledge.

\section{Academic imperialism: a new age of imperialism}

Imperialism is the state policy, practice, or advocacy of extending power and dominion, especially by direct territorial acquisition or by gaining political and economic control of other territories and peoples. $\underline{2}$

Historically, we learn so many empires have ruled the world. We know The Roman Empire (27 BC - 476 AD), The Mongol Empire (1206 until 1368), and The British Empire (late 16th to early 18th centuries). All of them as also the others were known for their thirst to exploit resources and left less to nothing for the natives.

Indonesia itself has been imperialized for 3.5 centuries and now the situation has not completely changed, especially in the academic ecosystem. This academic imperialism comes in a different form, using brains instead of ambush tactics, using emails instead of guns, and smiles instead of scowls. 
Imperialism itself has successfully shaped the perception of academics connecting quality with product branding, especially journal branding. In Indonesia we have a term for Scopus or WoS indexed-journals (the journals that are listed in Scopus or Web of Science database) and Q1 journals (the journals that are listed in the first quartile of Scimago Journal Rank) as prestigious journals. Hence the researchers that could publish their work in them would be automatically classified as prestigious researchers. More incentives, advantages, and opportunities then would be systematically poured to these researchers because the criteria of elite journals has been explicitly written in our national regulations regulating the key performance indicators and rank promotion criteria.

While they may argue that the criteria of journal selection are generic (e.g. good journals offer robust peer reviews), those criteria are wrapped in a way that would entice the academics for global acceptance.

Following those regulations, universities throughout Indonesia, regardless of their current state of infrastructure, their preliminary vision and mission, would immediately use the prestige-based indicators to create a roadmap of development plan, budgeting, and the allocation of human resources. Such situations are the exact copy of how we define "imperialism". The similar situation might also be verified in how the Indonesian Government orients budget for higher education, tenure evaluation, research grant, publication grant, publication award, and productive innovative research, especially the funding that goes to The Ministry of Research and Technology (Kementerian Ristek/BRIN) and The Ministry of Education and Culture (Kementerian Pendidikan dan Kebudayaan), and The Ministry of Finance (Lembaga Pengelolaan Dana Pendidikan/LPDP, or Indonesia Endowment Fund for Education). 


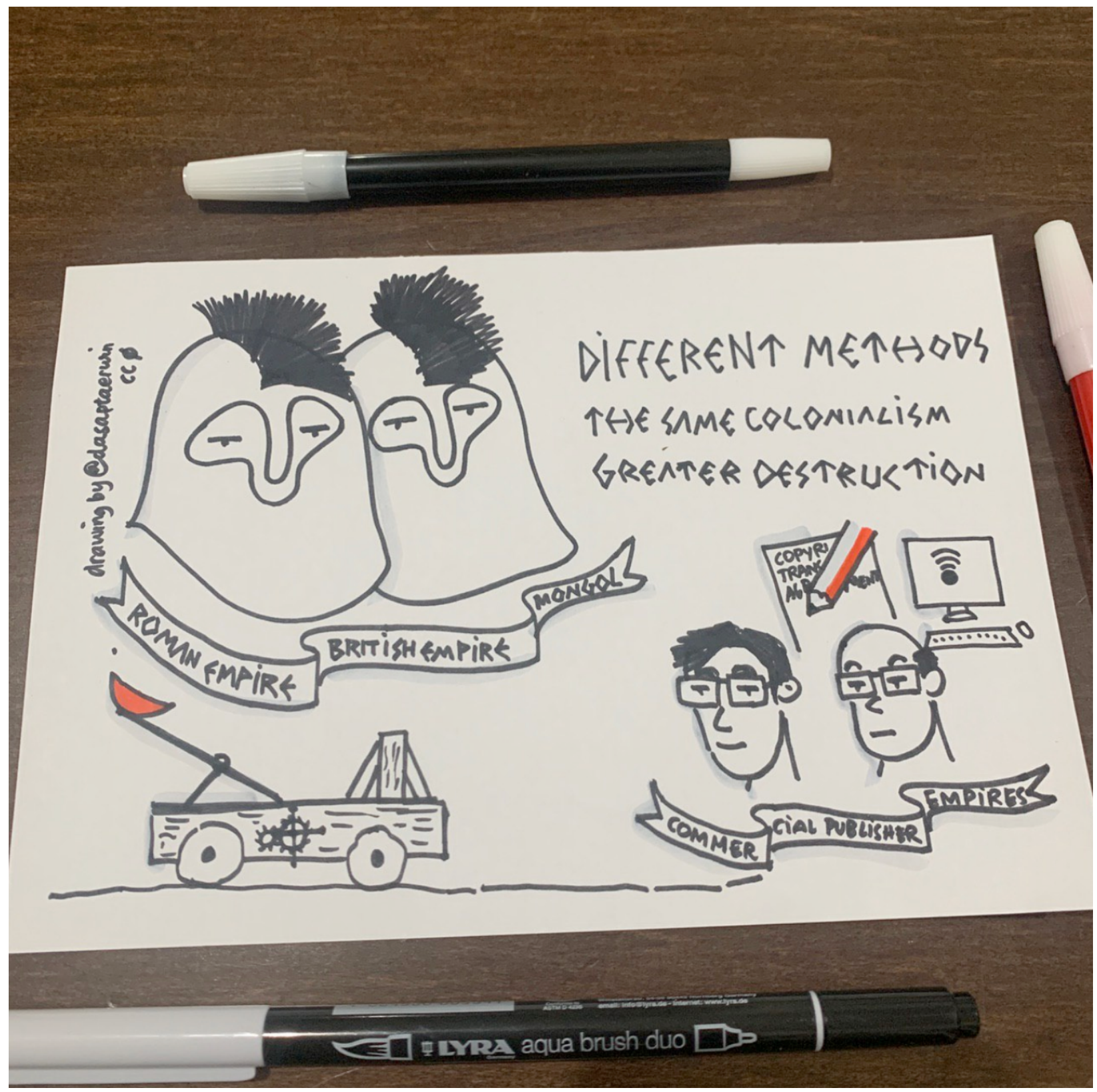

The new form of imperialism CCO from bit.ly/osdrawing $\underline{\underline{s}}$

\section{World Class University Rankings and the shifted poles}

The above-mentioned situations are very much connected to the rankings launched by three institutions: Quacquarelli Symonds ( $\underline{Q} \underline{S})$, Times Higher Education ( $\underline{\mathrm{THE}}$ ), Academic Ranking of World Universities ( $\underline{\text { ARWU) }}$. All three rankings are using metric/prestige-based indicators in their equations. Therefore the conversations of Indonesian academics would revolve around how we can get to the top of the chart, 
instead of how we stay relevant with the problems in society. The conversation in various meetings, most of which have been moved online, are not far from comparing notes on how to increase their world-class rankings and what new agreements they made with commercial publishers. Such conversation has no longer discussed the relevancy to solve the problem of the nations, but rather, on how to be on top of the chart as fast as they could using whatever means they could dispose of.

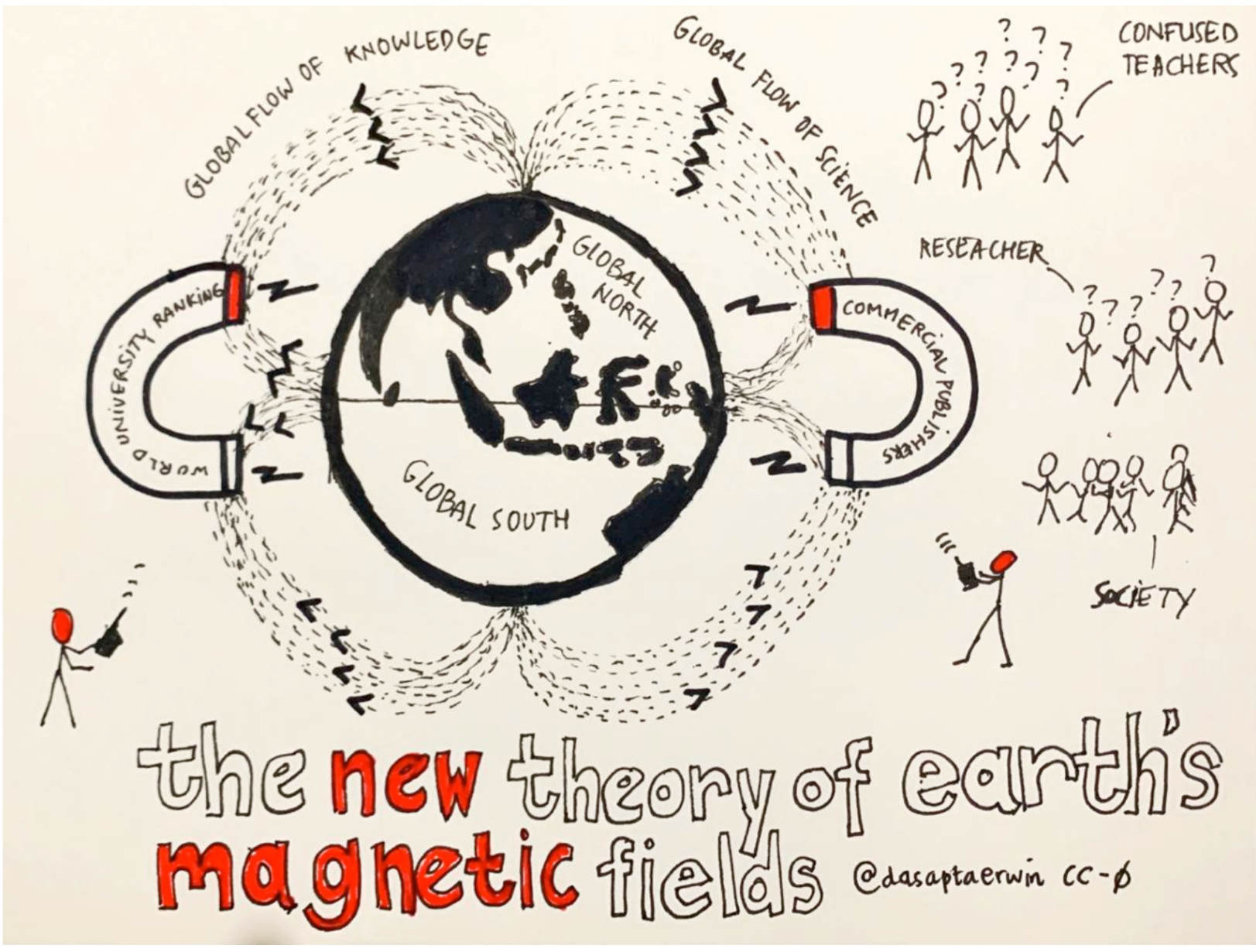

The new theory of earth's magnetic fields CCO from bit.ly/osdrawing $\underline{\underline{s}}$

\section{The time when a measure becomes a target}

As a result, the reorientation of rankings has been creating damaging_consequences, providing more proof of the validity of the phrase "When a measure becomes a target, it ceases to be a good measure," from Goodhart's Law. We came to this conclusion after evaluating popular university rankings, THE and QS, which generally consists of 
research metric (number of international publications in a certain database, number of citations), teaching metric (number of foreign staffs and foreign students), and reputation metric (based on a survey to external evaluator from international universities and industries).

\section{GOODHART'S LAW}

WHEN A MEASURE BECOMES A TARGET, IT CEASES TO BEA GOOD MEASURE

$\begin{array}{lll}\text { IF YOU } & \text { NUMBEROF } & \text { WEIGHT OF } \\ \text { MEASURE } & \text { NAILSMADE } & \text { NAILS MADE } \\ \text { PEOPLE ON... } & & \end{array}$
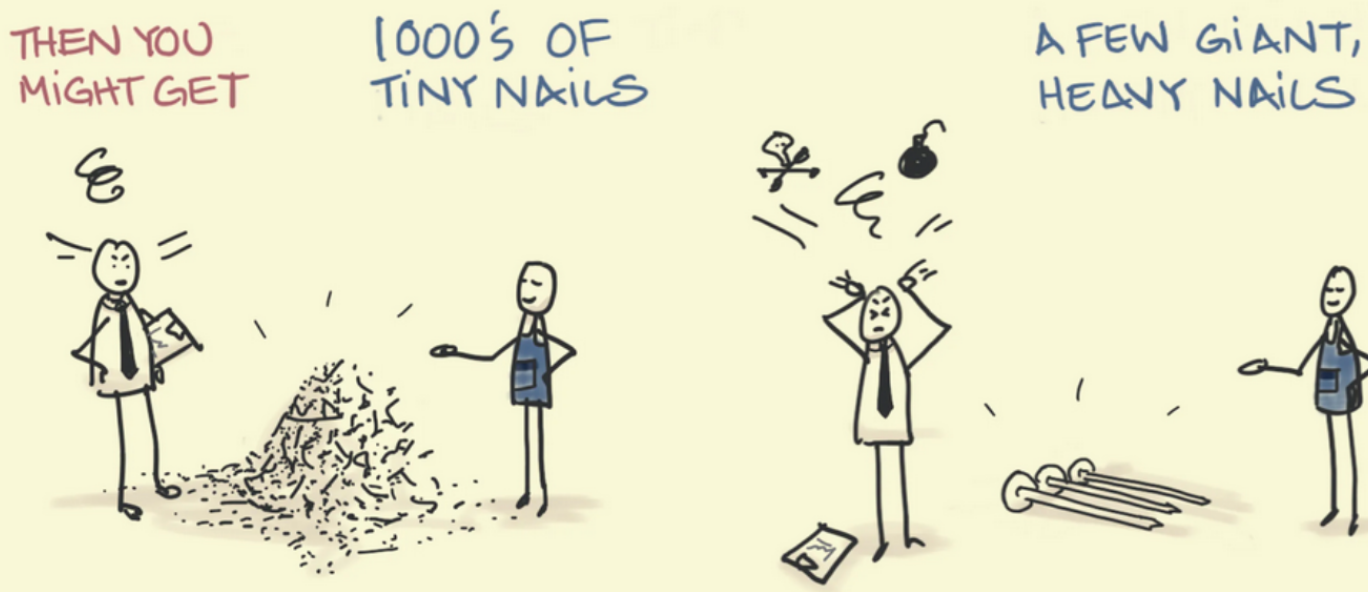
HEAVY NAILS
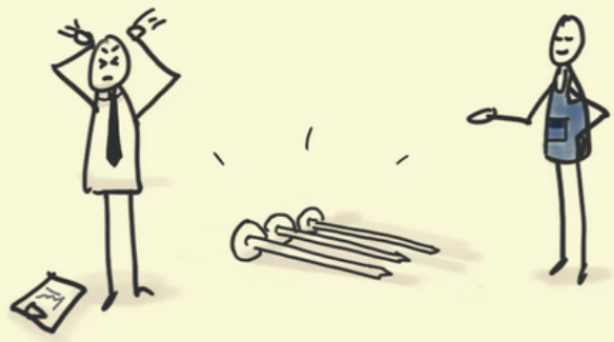

sketchplanations

Goodhart's law from Sketchplanations CC-BY-NC

Instead of coming up with good research and teaching activities, Indonesia's universities try to fit those metrics by inviting even hiring external researchers (usually diaspora or people with a good record of publication) with a contract of producing articles in prestigious journals. They might also invite prominent international researchers to spend sabbatical in Indonesia (known as adjunct 
professorship), with an agreement to focus on the publishing papers rather than to design meaningful research or teaching activities. For teaching metric, the universities are inviting foreign researchers to come to Indonesia for online or on-site guest lectures, therefore they can claim such activities as a proof of participation from foreign faculties in teaching and submit the claims to THE and QS. They might also create extension programs (e.g. summer schools) to invite foreign students with the motivation of claiming those classes to increase the number of foreign students participating in the teaching process. Moreover for reputation metric, Indonesia's universities have been building a database containing a list of potential researchers which might be invited by ranking providers respondents.

While expected to have real and substantial impact for the university, those strategies are considered practical which are designed only to increase chances of gaining more scores in research, teaching, and reputation measurement imposed by ranking providers. By launching such programs focusing to create more scores, it's fairly obvious that those faculties are failing to develop their critical thinking (considering potential flaws in the ranking methodology), although they endorse students to develop a skill of critical thinking on a daily basis. Aforesaid actions potentially_ resulting in budget mismatch and misallocation of resources following too much conflict of interests between what they need to do and what they want to achieve. These were the unintended consequences of Goodhart's Law that could potentially lead to dubious practices and mismeasurement in higher education.

\section{Diversity locked out}

According to the Higher Education Database (managed by the Ministry of Research and Technology and Higher Education), there are more than 4,500 universities (15\% of them are vocational education) with more than 36,000 programs, managed by almost 300,000 lecturers and attended by more than 8.7 million students. Those numbers are taken from all islands in Indonesia, meaning there will be disparities in infrastructure which will lead to the disparities of the qualification of lecturers and students.

Such a diverse situation of universities has not been completely considered in the performance measurement. All education levels, including vocational institutions, are expected to reallocate their resources to maximize their support in achieving the international rankings as targeted by the ministry in a firm national regulation. More 
fund flows to institutions, mainly the big universities in Java island as they most certainly can achieve the target, leaving behind so many small to mediums universities in the other islands.

The focus on the achievement of World Class University has made regulators of higher education as well as research and publication in Indonesia forget what is essential for embracing diversity in the Indonesian academic system. Meanwhile in Africa, there has been awareness to make de-imperialism efforts by encouraging "good-quality_ institutional archiving, instead of publication in globalized/Northern journals", Indonesia has "forgotten" (or "skipped") such concern on open infrastructure development. Even sadder, Indonesian academics, psychologically speaking, are afraid to save their work on the preprint server for fear of being indicated as double submission or multiple publications, which is categorized as a violation of academic integrity. It is not surprising that one of the Indonesian preprint servers, namely INARxiv, although is ever recognized as an important "source of information on the latest Indonesian research", it has experienced failure of sustainability; although soon supported by Indonesian Institute of Sciences (LIPI) with the establishment of $\underline{\text { RINarxiv. }}$

Especially in social sciences research, we also need to be open to the reality that the way of thinking of Indonesians (and Eastern society in general, compared to the Western) is a social cognition that is holistic rather than elementalist. It is not surprising that many Indonesian lecturers and researchers who complete their studies at overseas campuses, especially in the West (whereby they learned and were trained with lots of elementalist research approaches and methodologies), have the capacity to produce many scientific journal articles-in which most of the periodicals are indeed in favor of elementalist even atomistic scientific content (such as by presenting the flow of complex mediation and moderation relationships between variables). In other words, playing with World Class University rules of the game is made easier and enjoyable by just implementing those "imported methods" (especially if without doing_ self-criticism), even though there are risks of producing inaccurate, inappropriate, inapplicable, trivial, mediocre, simplistic, and alienated social knowledge, and even endangering Indonesian society. At the Faculty of Psychology, for example, the "defeat of Indonesian psychological research" coupled, paradoxically, with the "use of the 'sophistication' of Western psychology" was predicted almost two decades ago by a seasoned social psychologist. Sarlito Wirawan Sarwono, his name, stated that those phenomena, together with the reduction (even elimination) of the curriculum of Philosophy, Sociology, and Anthropology of communities in psychology faculties in 
Indonesia (to accommodate more Westernized-natural sciences-oriented psychological courses), would undermine the quality of psychological research in Indonesia. The desire to be "World Class Psychology Institutions" really ends up being an illusion. Why? Because what we need to become a truly world class are precisely the opposite practices from those stated above, i.e. the praxis which highly appreciates contextualities.

Adopting rankings recklessly has the risk of locking out diversity and preventing it to play an important role in strengthening local universities.

\section{Some takeaways}

Through this article, we recommend Indonesian Government prioritize the capacity development of physical (including digital) open infrastructure as well as leveraging_ human resources competency in order to support such infrastructure that appreciates the diversity of cognition, affection, conation, behavior and culture of the Indonesian people (as opposed to continuously feeding self-serving_academic system). For us, this is truly the mandate of the Indonesian Constitution (UUD 1945, especially UUD 1945 Article 28C paragraph 1, stating that "Indonesian citizens are entitled to education, science and technology, arts and culture in order to improve their quality of life") and Pancasila/The Five Principles, the foundation of the Indonesian state, especially the principles of democracy and social justice for all the peoples of Indonesia.

We suggest a rethink of rankings in form of three levels of intervention to mitigate the impact of academic imperialism and even de-imperialism, namely individual, cultural, and structural interventions. Those ones mentioned above lie at the structural level. Another thing that also needs to be considered at the structural level is the Government cooperation with international institutions in the context of the academic measurement ecosystem and public information services. For example, we still question the urgency of cooperation between Indonesia and certain commercial institutions to obtain their publication data. Why, for example, does Indonesia not optimize the collaboration with ORCID which has a more multi-axial measures of research achievement which includes not only the elements of publication, but also of people, organizations and resources involved in it? In addition, we need to constitute a system which can detect the correspondence between scientific publication and its significance for Indonesian public policy and every day's society practices. Reduce the 
use of the h-index as the primary criterion for the eligibility of Government's competitive research grant proposals. In this context, shifting our way in assessing and valuing research is not a form of mission impossible, following bold initiatives like Leiden Manifesto and SFDORA. The Government can intensify the use of the transparency_or credibility_history and other more qualitative, meaningful evidences from grantee candidates as the more prominent criteria, such as "articles in specialist publications (not being primarily scientific/scholarly journals), projects carried out in collaboration with civil-society actors, demonstrable civil-society effects of research, and civil-society recognition". Ultimately, Indonesian Government should have a clear open science roadmap as a part of Indonesian education roadmap, as Canada, $\underline{\text { Africa, }}$ and Malaysia do.

At the individual level, there should be a growth mindset among individual Indonesian academics. This mindset implies an individual's attitude that is open to all possible modes of conducting research and publication, followed by critical thinking on the limitations of ranking methodologies. Do not rush to categorize or label an act of research and publication as "unacceptable" just because it is not popular or available in the WEIRD (Western, educated, industrialized, rich, and democratic) countries. For example, recently, Anima, one of the oldest psychology journals in Indonesia, decided to publish all of its articles in bilingual, English version in the left column, and Indonesian version in the right column. Individual's growth mindset will view this Anima's pioneering work as a maturation phase of scientific journals in Indonesia in terms of democratizing the national language, namely Indonesian, while at the same time not ignoring the aspirations of internationalization. However, some will see such kind of effort as detrimental for journal inclusion in global indexation and want to reject this practice by_positing that all journal texts should be fully in English for indexing_purposes - and it represents a fixed mindset rather than growth mindset.

At the cultural level, raise critical consciousness towards the research and publication ecosystem from an early age. For example, do not let a single definition of "predatory publishing" and "plagiarism" dominate the world of Indonesian scholarship. Cultivate academic integrity that prioritizes not only intellectual modesty, but also intellectual honesty, instead. Our academic system must be honest and accurate in determining_ the criteria for predatory journals, for example. So far, our criteria for predatory journals are seemingly excluding most big_publishers, even though the essential criteria for predatory journals could touch on the operations dimensions of big publishing. Predatory publishing is not just, thus, "no peer review, no point". Beyond that, we need to change how we judge research. 
Cultural change in rewarding openness in research and publication practices must be strengthened. For example, in social media, reduce the frequency of congratulating institutions or individuals who "merely" have successfully placed their journals or articles on certain quantitative measures (e.g. high quartile or high impact factor). Look forward to complimenting the institutions or individuals if they publicly express the qualitative significances of the research their journals or articles contain, regardless of their metrics attributes, instead - moreover, if they have translated them into national language and in a form that is easier for the layman to digest, such as comics or infographics, semi-popular articles, or even game. Another one, in the era promoting "data as the new oil", let us encourage and appreciate data publication with the principle of as open as possible, as closed as necessary_- and data reuse as habitual practices that can strengthen Indonesian research diversity and reproducibility. As a consequence, in professorship tenure, diminish the myth that "data carry less weight than published journal articles". Besides, change the way we conduct bibliometric studies and interpret the results. Most bibliometric software and analyses today treat citation and authorship data as uncontextual data. Let us appreciate complexities by considering the context of the data as much as we are able to. 


\section{THREATS IN INDONES IA'S SCIENTIFiC PUBLICATIONS}

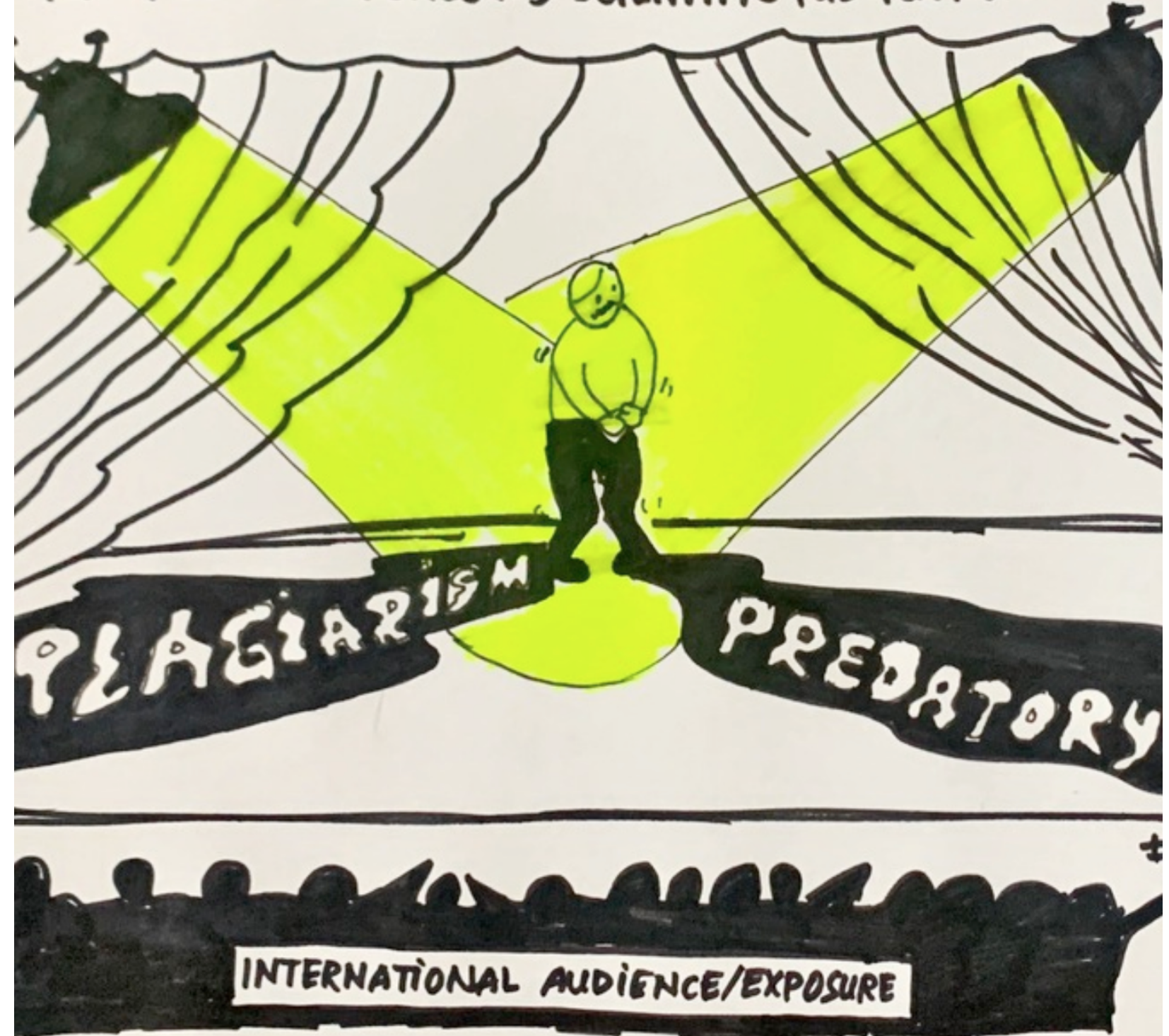

Threats in Indonesia's scientific publications (bit.ly/osdrawings CC0)

In addition, we need to seriously revive an alternative culture among academics who are able to counter the "publish or perish culture" that has also hit Indonesia. The Indonesian Open Science Team has participated in building this alternative culture by presenting the Indonesian translation of "Democratising_Knowledge" (the English version manuscript can be accessed here). This document, published by Education International, is an urgent call to all higher education consortia (including the research institutes and libraries within it) to jointly uphold academic freedom as well as to form 
and organize coalitions. Coalitions can be a strategic vehicle for social movement to negotiate on a structural level - through and together with Indonesian Government with the "big players" in the scientific publications and their measurements, i.e. world publishers and rankers. The aim of such a movement is for having more responsible practices benefitting science and society development rather than cultivating shortterm research and publication "survival” cultures (that stimulates herd mentality) and self-prestige. The coalition can also create and launch some gamechangers initiatives, such as "publish and flourish" culture using latest developments of open source technology; note that in Indonesia, we have also initiated GoPub in supporting that kind of culture.

With that said, we could say that academics have been captivated by their own mind. If we really love science and our country, freedom in research and publication should be our default mode of activities, i.e. to shift from imperialistic publish or perish to nourishing publish and flourish.

This article was written to commemorate the passing of Dr. Jon Tennant on the 9th of April 2020 in Ubud, Bali. He has shared a powerful voice in open science. May his soul rest in peace.

\section{Footnotes}

1. Inspired by "If you Love Somebody Set Them Free," a song by Sting.

2. This definition is based on that found in the Encyclopedia Britannica:

https://www.britannica.com/topic/imperialism $\subseteq$ 